\title{
Methylprednisolone Acetate
}

National Cancer Institute

\section{Source}

National Cancer Institute. Methylprednisolone Acetate. NCI Thesaurus. Code C48003.

The acetate salt of a synthetic glucocorticoid receptor agonist with immunosuppressive and antiinflammatory effects. Methylprednisolone acetate is converted into active prednisolone in the body, which activates glucocorticoid receptor mediated gene expression. This includes inducing synthesis of anti-inflammatory protein IkappaB-alpha and inhibiting synthesis of nuclear factor kappaB (NF-kappaB). As a result, proinflammatory cytokine production such as IL-1, IL-2 and IL-6 is down-regulated and cytotoxic T-lymphocyte activation is inhibited. Therefore, an overall reduction in chronic inflammation and autoimmune reactions may be achieved. 